\title{
The Spatial Evolution Analysis of Manufacturing Industrial Gravity Centre of Guangdong Province
}

\author{
Fangfang Wang \\ School College of Economics, Jinan University, Guangzhou, China \\ Email: JNU0612@163.com
}

How to cite this paper: Wang, F.F. (2018) The Spatial Evolution Analysis of Manufacturing Industrial Gravity Centre of Guangdong Province. American Journal of Industrial and Business Management, 8, 721-734.

https://doi.org/10.4236/ajibm.2018.83049

Received: March 5, 2018

Accepted: March 25, 2018

Published: March 28, 2018

Copyright $\odot 2018$ by author and Scientific Research Publishing Inc. This work is licensed under the Creative Commons Attribution International License (CC BY 4.0).

http://creativecommons.org/licenses/by/4.0/

\begin{abstract}
This paper chooses the manufacturing added value as the main research indicator, using gravity analysis method to analyze the spatial evolution of manufacturing industry in Guangdong province from 2006 to 2015, decomposing the manufacturing gravity and calculating the grey correlation degree. The results show that: 1) manufacturing gravity is mainly distributed in Dongguan, it is characterized by moving eastward; 2) the labor-intensive manufacturing gravity is in the southwest and northeast, capital-intensive manufacturing gravity is in the northwest, while technology-intensive manufacturing gravity is in the southeast; 3 ) the whole manufacturing is the most relevant to the technology-intensive manufacturing, and the least is labor-intensive. The shift of the technology-intensive manufacturing industry has the greatest impact on the whole manufacturing; 4) the effect of manufacturing transfer on the balance of manufacturing in Guangdong province is not obvious. In order to realize the balanced development of manufacturing spatial distribution, we should further strengthen the manufacturing upgrading in the less developed areas and improve the technical development level of the backward areas.
\end{abstract}

\section{Keywords}

Manufacturing, Spatial Pattern, The Center of Gravity, The Grey Correlation Degree

\section{Introduction}

Since the reform and opening-up, Guangdong province has rapidly developed into an economy-developed province of China, but the imbalance of regional development has been an important problem faced by Guangdong province in 
recent years. The manufacturing output of the Pearl River Delta region accounted for $82.54 \%$ of Guangdong's manufacturing output, and its manufacturing employment accounted for $82.86 \%$ of the province in 2015 , mainly as the center-periphery structure centered on the Pearl River Delta.

In order to promote the industrial upgrading of the Pearl River Delta region, some of the lower value-added industries need to be transferred out, and in order to develop the local economy, east, west, north of Guangdong need to attract investment. Therefore, in order to promote the balanced development of economy in Guangdong province, Guangdong provincial government issued the "Views on the north mountains, east-west wings and the Pearl River Delta to promote industrial transfer" in 2005, enabling the Pearl River Delta and other regions of Guangdong to jointly establish industrial transfer industrial park. In May 2008, "the decision to promote industrial transfer and labor transfer of CPC Guangdong Provincial party committee and the Guangdong Provincial People's government" was issued, which began the industrial and labor double transfer strategy. As a large manufacturing province, the spatial distribution of manufacturing industry has an important influence on the balanced and coordinated development of economy in Guangdong province. Therefore, under the background of industrial transfer policy, this paper analyzes the evolvement process of the spatial pattern of manufacturing industry, outlines the characteristics of the spatial evolution of the manufacturing industry in Guangdong province. It provides some theoretical basis for local government to adopt pertinence measures and policy support, adjust the space structure of manufacturing industry, promote the space transfer of manufacturing industry, and optimize the development of manufacturing industry and realize the balanced development of manufacturing industry in Guangdong province.

\section{Literature Review}

From the existing domestic and foreign scholars on the manufacturing space distribution research methods, it mainly uses the traditional indexes, such as location entropy, Gini coefficient, Thiele Index, Herfindahl Index and EG index, to measure the spatial difference and agglomeration state of manufacturing distribution [1]-[6]; or considering spatial perspective when analyzing the spatial distribution of manufacturing industry, using exploratory spatial analysis [7]. Previous studies have only illustrated the overall spatial distribution of the manufacturing sector, or the distribution of manufacturing in different regions. In order to reflect the overall distribution and dynamic transfer process of manufacturing overall distribution over the years, the center of gravity model is introduced. The method of gravity analysis is widely used in the study of social, economic and natural resources [8] [9] [10] [11]. Geographical explanation of manufacturing center of gravity is the center of increasing value space distribution of regional manufacturing industry. As the research tool of manufacturing space structure evolvement, manufacturing center of gravity will be shifted cor- 
respondingly with the change of manufacturing development level, manufacturing structure and related policies.

The research on the gravity center of domestic scholars began in the 1970s, which is later compared with foreign countries. On the one hand, it shows the research on the change of gravity center such as economy, agriculture and industry: Jie Fan, Taupman W. [12] first studied the change of gravity center of China's rural industry since reform and opening-up. Minliang Zhou [13] analyzed the relationship between China's economic gravity center and regional disparity. Xihua Sun [14] studied the shift of gravity center of three industries in Shandong province, and put forward the strategy of sustainable development. Jiajun Qiao, Xiaojian Li [15] analyzed the shifting path of China's economic gravity center in the past 50 years. On the other hand, it shows the relationship between economic gravity center and industrial gravity center: by using the method of gravity analysis, Zongxian Feng, Jianshan Huang [16] analyzed the dynamic characteristics of economic center of gravity and industrial center of gravity in detail from the aspects of moving direction, distance, speed and reason, and compared the relationship between industrial center of gravity and economic center of gravity. Lei Yang, Peng Du, Bin Xia [17], according to the center of gravity analysis method,contrasted the relationship between the economic center of gravity and the industrial center of gravity since the reform and opening-up. Jun Yan, Zhanghua Wang [18] described the evolution of China's population, economy and industry center of gravity in the past 30 years and analyzed the evolution trajectory. Zonglong Cao, Songlin Chen [19] studied the change trajectory of economic and industrial center of gravity in Fuzhou from1968 to 2009.

Previous research on the center of gravity of manufacturing industry are generally from the following two aspects : on the one hand, from the provincial level analysis, Sanmang Wu, Shantong Li [20] used the center of gravity analysis method to calculate the direction and distance of China's manufacturing center of gravity space movement, the study found that most labor-intensive manufacturing industry mainly concentrated in the southeast coastal areas, the manufacturing center of gravity experienced the first eastward and southward, then the trend of changes in the west and north; on the other hand, from the whole manufacturing industry, Lei Sun, Xiaoping Zhang [21] described the evolution of the spatial distribution of the manufacturing industry in Beijing, and quantitatively described the dynamic factors that affect the layout of the manufacturing industry by using the decomposition analysis of the gravity shift.

Different from the previous literatures, this paper firstly analyzes the change of the manufacturing gravity and its possible causes, it can be seen intuitively that the spatial equilibrium of manufacturing industry and the direction of space transfer in manufacturing industry in Guangdong province, since the introduction of industrial transfer in 2005. And then divides the manufacturing industry into labor-intensive, capital-intensive and technology-intensive according to the 
factor density of different industries. Because of the different factor-intensive has different possible transfer and influence factors, it is more persuasive to analyze the change of center of gravity of different factor-intensive manufacturing industry. Finally, the influence of different factor-intensive manufacturing industries on the whole manufacturing gravity is analyzed, which factor-intensive manufacturing has the greatest impact on the spatial distribution of manufacturing, in order to ensure the balanced development of manufacturing industry in Guangdong province, the factor-intensive manufacturing industry will be considered.

\section{Research Methods and Data}

\subsection{Definition of Manufacturing Classification and Data Source}

The data used in this paper are from "Guangdong Province Statistical Yearbook 2007-2016", data are collated, and using GIS software to deal with the data. In the study of the selection of indicators, because the two-digit manufacturing value added data only begin from 2006, so we use the data from 2006 to 2015, and the whole manufacturing value added data are added through the two-digit manufacturing industry added value. This paper draws on the classification method of manufacturing industry [22] of Ligao Yang and Rui Xie. According to the difference of factor density in manufacturing industry, 28 industries are divided into labor-intensive industry, capital-intensive industry and technologyintensive industry. See Table 1.

\subsection{The Research Methods}

\subsubsection{Centre of Gravity Analysis}

The calculation formula of the center of gravity:

Table 1. Classification of manufacturing industry segments based on factor density.

\begin{tabular}{|c|c|}
\hline Item & Segments \\
\hline $\begin{array}{l}\text { Labor intensive } \\
\text { manufacturing }\end{array}$ & $\begin{array}{l}\text { Agricultural and sideline products processing industry, food manufacturing, } \\
\text { textile industry, textile and apparel (material, cap) manufacturing, leather } \\
\text { fur feathers (fine hair) and its products, wood processing and bamboo } \\
\text { rattan palm grass, furniture manufacturing, copy of printing and recording } \\
\text { media, cultural and educational supplies manufacturing, rubber products, } \\
\text { plastic products, non-metallic mineral products, fabricated metal products }\end{array}$ \\
\hline $\begin{array}{l}\text { Capital intensive } \\
\text { manufacturing }\end{array}$ & $\begin{array}{l}\text { Beverage manufacturing, tobacco manufacturing, paper and paper products, } \\
\text { oil processing and coking and nuclear fuel, chemical raw materials and } \\
\text { chemical products manufacturing industry, chemical fiber products, ferrous } \\
\text { metal smelting and rolling processing industry, non-ferrous metal smelting } \\
\text { and rolling processing industry, general equipment manufacturing industry }\end{array}$ \\
\hline $\begin{array}{l}\text { Technology intensive } \\
\text { manufacturing }\end{array}$ & $\begin{array}{l}\text { Medical manufacturing, specialized equipment manufacturing, } \\
\text { transportation equipment manufacturing, electrical machinery and } \\
\text { equipment manufacturing, communication equipment computer and other } \\
\text { electronic, instrument and instrument culture office machinery }\end{array}$ \\
\hline
\end{tabular}




$$
M_{i}\left(x_{i}, y_{i}\right)=\left[\frac{\sum_{i=1}^{n} u_{i} x_{i}}{\sum_{i=1}^{n} u_{i}}, \frac{\sum_{i=1}^{n} u_{i} y_{i}}{\sum_{i=1}^{n} u_{i}}\right]
$$

In the formula, $M_{i}\left(x_{i}, y_{i}\right)$ is the $\mathrm{i}$-year center of gravity coordinates of the whole research area, and the $u_{i}$ is the regional manufacturing output value of the prefecture-level region.

The measurement formula of the distance of the center of gravity showed a movement of $d_{m-k}(\mathrm{~km})$ in $k-m$ years, if $k \leq h \leq m$, the mobile distance from $\mathrm{h}$ to $m$ :

$$
\begin{gathered}
d_{h-k}=c \cdot \sqrt{\left(x_{h}-x_{k}\right)^{2}+\left(y_{h}-y_{k}\right)^{2}} \\
d_{m-k}=c /(m-k) \cdot \sum_{h=k}^{m} d_{h}
\end{gathered}
$$

where $d$ indicates the distance of manufacturing center of gravity movement in a certain period of time; $h, k$ respectively indicate different two years, $\left(x_{h}, y_{h}\right)$, $\left(x_{k}, y_{k}\right)$ respectively indicate the geographical coordinates of the manufacturing center of gravity.

$c$ is the coefficient of geographical coordinate unit converted to plane distance, for constant 111.111; $c^{*}\left(x_{h}-x_{h}\right), c^{*}\left(y_{h}-y_{k}\right)$ respectively indicates the moving distance of the manufacturing center of gravity from $k$ to $h$ in the region in longitude and dimension.

\subsubsection{Grey Relational Degree Analysis}

Grey relational degree analysis: development situation analysis is based on the approximate degree of curve shape of various factors, this analysis is to find the relationship between the subsystems [23].

$$
\begin{gathered}
\gamma\left(x_{0}(k): x_{i}(k)\right)=\frac{\min _{i} \min _{k}\left|x_{0}(k)-x_{i}(k)\right|+\xi \max _{i} \max _{k}\left|x_{0}(k)-x_{i}(k)\right|}{\left|x_{0}(k)-x_{i}(k)\right|+\xi \max _{i} \max _{k}\left|x_{0}(k)-x_{i}(k)\right|} \\
\gamma\left(x_{0}: x_{i}\right)=\frac{1}{n} \sum_{k-1}^{n} \gamma\left(x_{0}(k): x_{i}(k)\right)
\end{gathered}
$$

Type: $x_{0}(k)$ is the selected reference data column, $x_{i}(k)$ is compared to the series, $i=1,2,3, k=1,2,3,10$. The $\xi$ is the resolution factor, which takes a value between $0-1$ and usually takes $0.5, \gamma\left(x_{0}: x_{i}\right)$ is a grey correlation coefficient.

\section{Distribution and Evolution of Manufacturing Gravity Center in Guangdong Province}

In 2006-2015, the coordinate change of manufacturing center of gravity in Guangdong province is shown in Figure 1 and Table 2.

First, from the distribution of the center of gravity, manufacturing center of gravity mainly change in $113.473302^{\circ} \mathrm{E}-113.668506^{\circ} \mathrm{E}, 22.88144^{\circ} \mathrm{N}-22.944761^{\circ} \mathrm{N}$, focus on Dongguan. From 2006 to 2015, its centre of gravity has deviated from 


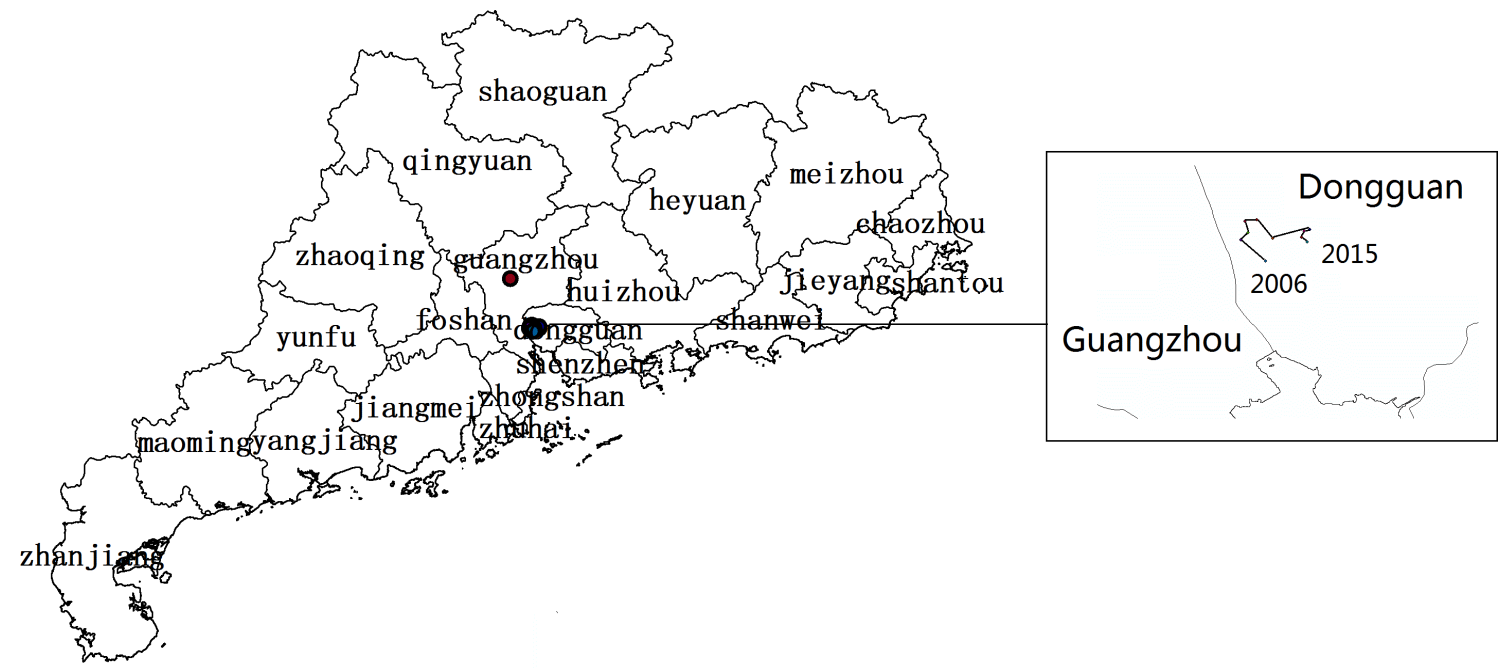

Figure 1. The change track of overall gravity center of manufacturing industry in Guangdong province in 2006-2015.

Table 2. The change of the overall gravity center of manufacturing industry in Guangdong province in 2006-2015.

\begin{tabular}{ccccc}
\hline Year & \multicolumn{2}{c}{ Barycentric coordinates } & Mobile distance & Movement Direction \\
\hline 2006 & $113.6019^{\circ} \mathrm{E}$ & $22.9091^{\circ} \mathrm{N}$ & & \\
2007 & $113.5736^{\circ} \mathrm{E}$ & $22.9336^{\circ} \mathrm{N}$ & 3.9736 & Northwest \\
2008 & $113.5820^{\circ} \mathrm{E}$ & $22.9418^{\circ} \mathrm{N}$ & 1.2497 & Northeast \\
2009 & $113.5781^{\circ} \mathrm{E}$ & $22.9548^{\circ} \mathrm{N}$ & 1.4951 & North by west \\
2010 & $113.5920^{\circ} \mathrm{E}$ & $22.9565^{\circ} \mathrm{N}$ & 1.4331 & East by north \\
2011 & $113.6100^{\circ} \mathrm{E}$ & $22.9349^{\circ} \mathrm{N}$ & 3.0187 & Southeast \\
2012 & $113.6533^{\circ} \mathrm{E}$ & $22.9451^{\circ} \mathrm{N}$ & 4.5797 & East by north \\
2013 & $113.6464^{\circ} \mathrm{E}$ & $22.9435^{\circ} \mathrm{N}$ & 0.7295 & Southwest \\
2014 & $113.6437^{\circ} \mathrm{E}$ & $22.9365^{\circ} \mathrm{N}$ & 0.8201 & Southwest \\
2015 & $113.6499^{\circ} \mathrm{E}$ & $22.9312^{\circ} \mathrm{N}$ & 0.8682 & Southeast \\
\hline
\end{tabular}

the geographical center of Guangzhou city $\left(113.4153^{\circ} \mathrm{e}, 23.33545^{\circ} \mathrm{n}\right)$, indicating that the spatial distribution of manufacturing industry in Guangdong province has been unbalanced. From 2006 to 2009, it gradually moved to the direction of the geographical center, the distances between manufacturing center of gravity of each year and geographical center of Guangdong province are $50.9349 \mathrm{~km}$, $47.4653 \mathrm{~km}, 46.8208 \mathrm{~km}, 45.3319 \mathrm{~km}$, indicating that the spatial difference of manufacturing industry gradually narrowed in this stage, and moved away from the geographical center after 2010, and its spatial difference gradually expanded.

Second, from the direction of the center of gravity movement, since 2006, the direction of the whole manufacturing gravity has been to the northwest, then to the southeast trend. From the moving trajectory of the manufacturing industry, it can be seen that the eastward shift is far greater than the northward shift, moving eastward $0.048^{\circ}$ to the east and $0.022^{\circ}$ to the north. It is indicated that 
the change of manufacturing industry has changed larger in north-south direction than east-west direction since 2006, and the main trend of manufacturing distribution is moving from west to east. According to the proportion of the total output value of the whole province, the manufacturing industry of Guangdong province was mainly concentrated in Shenzhen (24\%), Guangzhou (17.4\%), Foshan (16.3\%) and Dongguan (11.7\%) and other cities in 2006. Foshan (15.6\%), Guangzhou (15.1\%) and Dongguan (9.2\%) and other cities, it can be seen the major distribution of the city's share of the proportion are declining trend from 2006 to 2015, while Huizhou from 3.8\% in 2006 increased to 5.7\% in 2015, Jieyang from $0.8 \%$ in 2006 increased to $2.9 \%$ in 2015 , due to the cities that the proportion decreased are citied in the southwest direction in 2006, while Huizhou and Jieyang in its northeast direction, the whole manufacturing gravity of Guangdong province shifted to the northeast in 2015.

Third, in different time period, the difference of movement direction of the whole manufacturing gravity is big. During the period 2006-2010, the direction of the center of gravity movement of manufacturing industry in Guangdong province was north by west, mainly to the north. Manufacturing center of gravity is located in east longitude $113.6019^{\circ}$, northern latitude $22.9091^{\circ}$ in 2006 , to the east longitude $113.5920^{\circ}$, north latitude $22.9565^{\circ}$ in 2010 , moved northward $0.0474^{\circ}$, and moved westward $0.0098^{\circ}$. The main trend was to northward, and the center of gravity was always located in Dongguan. During this period, the main reason of Guangdong's manufacturing center of gravity moving to the north west-northwest is that the related policies of industrial transfer industrial park were promulgated successively in Guangdong province. The Pearl River Delta region actively transfers some low value-added labor-intensive industries, vigorously constructs the modern industrial system, accelerates the structural transformation and escalation, and promotes the rapid economic growth in the north, west and east of Guangdong. From the change of proportions that city added value of Guangdong added value, Shenzhen and Dongguan change most obvious. Shenzhen from $24 \%$ in 2006 fell to $20.9 \%$ in 2010, Dongguan from $11.7 \%$ in 2006 down to $8 \%$ in 2010 , Shenzhen is located in the southeast direction of the manufacturing industry of 2006, while the proportion of the value added in the cities such as Qingyuan, Huizhou and Guangzhou in the northwest direction of manufacturing center of gravity shows an increasing trend in the 2006, so the center of gravity of the manufacturing industry in 2010 is moving north west and mainly moving northward. After 2010, the center of gravity of manufacturing industry in Guangdong province is moving east to south. In order to upgrade the manufacturing industry and promote the coordinated development of the region, the manufacturing industry of the Pearl River Delta began to transfer to the northwest of Guangdong, and at the same time, in order to provide conditions for the industry upgrading of the transfer areas. Better use of advanced technology to develop high value-added industries, the percentage of added value of some transfer areas present a rising trend, such as Huizhou and Shenzhen. It can be seen from the change of the ratio of added value of manu- 
facturing industry in all cities that the proportion of Guangzhou, Foshan, Zhongshan and Jiangmen reduced 3.3\%, 2.3\%, $1.3 \%$ and $1.6 \%$ respectively from 2010 to 2015 , the proportion of Huizhou and Shenzhen cities increased by $1.4 \%$ and $1.7 \%$ respectively. As a result, the manufacturing center of gravity moved east by south in 2015 .

Four, from the Moving distance of the manufacturing industry's overall center of gravity. The manufacturing industry's overall center of gravity moving distance showed a trend northward movement from 2006 to 2010, the displacement distance is $5.340196 \mathrm{~km}$, the trajectory direction overall appears eastward movement from 2011 to 2015, the displacement distance is $6.563871 \mathrm{~km}$. Manufacturing center of gravity moving distance of the smallest year is 2013, only to the southwest to move $0.7295 \mathrm{~km}$, manufacturing center of gravity moving distance of the largest year is 2012, east to north direction of the move $4.5797 \mathrm{~km}$. The yearly changes of shifting distance of manufacturing center of industry in Guangdong province is relatively large, which indicates that the spatial distribution of manufacturing industry in Guangdong province is influenced by relevant policies and economic environment.

\section{Manufacturing Gravity Decomposition}

\subsection{Analysis of the Spatial Evolution of Manufacturing Gravity}

In order to further analyze the spatial change of the center of gravity of manufacturing industry in Guangdong province, the paper calculates the distribution status of the center of gravity of manufacturing industry in Guangdong province by using the center of gravity analysis. See Figure 2 .

Labor-intensive manufacturing center of gravity mainly changes in $113.554^{\circ} \mathrm{e}-$

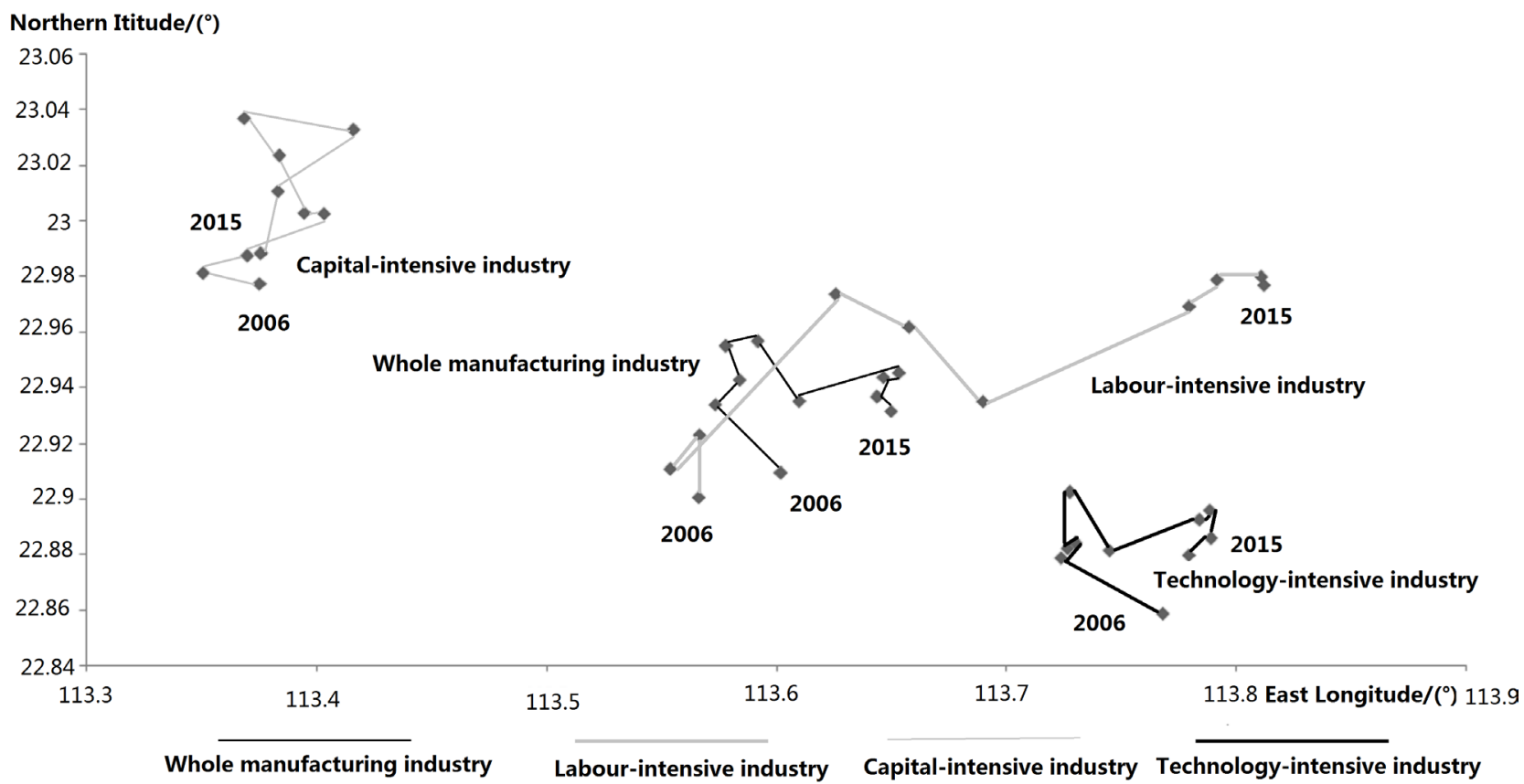

Figure 2. The shifting locus of gravity center of manufacturing industry in Guangdong province in 2006-2015. 
$113.8118^{\circ} \mathrm{e}, 22.8559^{\circ} \mathrm{n}-22.9798^{\circ} \mathrm{n}$, focus on the junction of Guangzhou Panyu and Dongguan. The center of gravity of labor-intensive manufacturing is generally moving east to north. The center of gravity of capital-intensive manufacturing mainly changes in $113.3511^{\circ} \mathrm{e}-113.4164^{\circ} \mathrm{e}$ and $22.9771^{\circ} \mathrm{n}-23.0674^{\circ} \mathrm{n}$, focusing on the north of Guangzhou Panyu district.

Capital-intensive manufacturing is mainly in the north-south direction of the movement, from 2006 to 2010 overall to northward movement, from 2011 to 2015 overall to southward movement. The center of gravity of technology-intensive manufacturing is mainly in the $113.7236^{\circ} \mathrm{e}-113.7888^{\circ} \mathrm{e}$ and $22.8583^{\circ} \mathrm{n}$ $22.902^{\circ} \mathrm{n}$, the center of gravity is distributed in the south of Dongguan. The technology-intensive manufacturing industry presents a trend of 2006-2010 to the north to west and 2010-2015 to the south to east direction.

The evolution trajectory of the centers of gravity of the whole manufacturing industry and the three manufacturing industry: 1) from the space relative position, the gravity of labor-intensive manufacturing industry is in the southwest and northeast direction of the whole manufacturing gravity, capital-intensive manufacturing industry in the northwest direction of the whole manufacturing gravity, technology-intensive manufacturing center of gravity in the southeast direction. The geographical concentration of different factor-intensive manufacturing industry varies greatly. 2) from the relative distance between the whole manufacturing gravity center and different factor-intensive manufacturing industry, the gravity of labor-intensive manufacturing industry is the most nearest one in the manufacturing industry from 2006 to 2011. It shows that labor-intensive manufacturing industry has the most influence on the whole manufacturing gravity, and the capital-intensive manufacturing industry has the least influence on the whole manufacturing gravity. The gravity of technology-intensive manufacturing industry is the closest to the whole manufacturing gravity from 2012 to 2015. It shows that the technology-intensive manufacturing industry has the greatest influence on the whole manufacturing gravity instead of labor-intensive manufacturing. 3) from the shifting direction of the gravity center of the whole and different factor-intensive manufacturing industry, the direction of the gravity shift of manufacturing industry and technology-intensive manufacturing is first to northwest, and then to the southeast. Capital intensive is mainly in the north-south direction, technology-intensive manufacturing industry presents a trend toward the east by north. 4) from the shift distance of the whole manufacturing gravity and three major industries gravity, the order of the movement for 10 years: labor-intensive manufacturing industry $(26.558809 \mathrm{~km})>$ whole manufacturing $(5.498233 \mathrm{~km})>$ technology-intensive manufacturing center of gravity $(2.607247 \mathrm{~km})>$ capital-intensive manufacturing center of gravity $(1.227959$ $\mathrm{km}$ ). Labor-intensive manufacturing industry has the biggest change distance and its annual change speed is the most obvious, which shows that it is most obviously affected by relevant policies and economic environment, the second is technology-intensive, and the change of capital-intensive manufacturing gravity 
is the smallest.

\subsection{Measurement of the Correlation between the Center of Gravity of Manufacturing Industry and the Center of Three Industries}

The change of the overall economic gravity center of Guangdong's manufacturing industry as a reference sequence from 2006 to 2015, compared with the corresponding years of labor-intensive manufacturing, capital-intensive manufacturing and technology-intensive manufacturing industry, measuring he correlation between the different industries and the whole manufacturing on east-west and north-south directions. The correlation matrix of the latitude and longitude between the overall center of gravity of the manufacturing industry and the three industrial centers is computed, as shown in Table 3.

The correlation coefficients of the whole manufacturing gravity and labor-intensive manufacturing, capital-intensive manufacturing and technology-intensive manufacturing are $0.5292,0.6539$ and 0.8882 respectively from 2006 to 2015 . It is indicated that technology-intensive manufacturing industry has the most relevant degree with the whole manufacturing industry, the second is capital-intensive manufacturing, and the weakest correlation is labor-intensive manufacturing. The correlation coefficients between the overall economic center of manufacturing industry and labor-intensive manufacturing, capital-intensive manufacturing and technology-intensive manufacturing industry are $0.5545,0.6547$, and 0.8692 from 2006 to 2015 . Which shows that technology-intensive manufacturing industry is the most correlated with economic center of gravity in dimension, followed by capital-intensive, the weakest correlation is labor-intensive manufacturing.

The order of degree correlation degree between the whole manufacturing

Table 3. The gray correlation matrix of the whole manufacturing gravity and the center of gravity of the three industries in 2006-2015.

\begin{tabular}{ccccccc}
\hline & \multicolumn{3}{c}{ Longitude correlation } & \multicolumn{3}{c}{ Dimensional correlation } \\
\cline { 2 - 7 } & Labor intensive & Capital intensive & Technology-intensive & Labor intensive & Capital intensive & Technology intensive \\
\hline 2006 & 0.339174 & 0.929523 & 0.709874 & 0.522569 & 0.626213 & 0.857874 \\
2007 & 0.412444 & 0.578338 & 0.89481 & 0.496558 & 0.671137 & 1 \\
2008 & 0.351235 & 0.467494 & 0.958544 & 0.338726 & 0.47874 & 0.873316 \\
2009 & 0.699869 & 0.726079 & 0.920627 & 0.781635 & 0.581701 & 0.557914 \\
2010 & 0.909353 & 0.712204 & 0.898204 & 0.776092 & 0.952617 & 0.985871 \\
2011 & 0.890814 & 0.785173 & 0.884011 & 0.656303 & 0.919132 & 0.967361 \\
2012 & 0.508049 & 0.75283 & 0.826612 & 0.656956 & 0.742485 & 0.929684 \\
2013 & 0.431874 & 0.551671 & 1 & 0.494463 & 0.513315 & 0.770466 \\
2014 & 0.368083 & 0.473132 & 0.974774 & 0.419439 & 0.521805 & 0.85971 \\
2015 & 0.380898 & 0.562175 & 0.814794 & 0.402602 & 0.539662 & 0.890243 \\
\hline
\end{tabular}


gravity and the three major industries in the longitude and dimension is consistent. Overall, the technology-intensive manufacturing industry is the most relevant to the whole manufacturing industry, that is, the growth of technology-intensive manufacturing industry has the strongest effect on the movement of the whole manufacturing gravity, indicating that the overall growth of manufacturing industry in Guangdong province is more reflected in the growth of technologyintensive manufacturing. Both in terms of longitude and dimension, labor-intensive manufacturing industry has the smallest correlation with manufacturing industry, which shows that the change of the spatial distribution of labor-intensive manufacturing industry has little influence on the change of the overall center of gravity of the manufacturing industry. From the change of the center of gravity of manufacturing industry, it can be seen that although the change of center of gravity of labor-intensive manufacturing is more obvious, the overall manufacturing gravity changes little from 2006 to 2015, and the relative policies have less effect on the balanced development of manufacturing industry in Guangdong province. Because the proportion of labor-intensive manufacturing industry is small, the grey relation degree between the center of gravity of labor-intensive manufacturing industry and the whole center of manufacturing is small, so its spatial change has less influence on the whole manufacturing gravity, and the effect of industrial transfer is not obvious to realize the balanced development of Guangdong province.

\section{Conclusions}

This paper takes city-area manufacturing added value of Guangdong province as the main research index in 2006-2015. The center of gravity analysis method is used to analyze the spatial pattern evolution of manufacturing industry in Guangdong province. On this basis, the following conclusions are drawn:

Firstly, from the distribution of the center of gravity, the overall manufacturing gravity mainly changes between $113.473302^{\circ} \mathrm{e}-113.668506^{\circ} \mathrm{e}, 22.88144^{\circ} \mathrm{n}-$ $22.944761^{\circ} \mathrm{n}$, focus on the Dongguan. It presents a movement of east by north, mainly to east of 5.4982 kilometers. The distribution of center of gravity has deviated from the geographical center of Guangzhou city $\left(113.4153^{\circ} \mathrm{e}, 23.33545^{\circ} \mathrm{n}\right)$, which shows that the spatial distribution of manufacturing industry in Guangdong province has been unbalanced, and the spatial difference of manufacturing industry in Guangdong province has shrunk gradually from 2006 to 2009. After 2010, its spatial difference is gradually expanding.

Secondly, under the background of the transfer and the upgrading of manufacturing industry in Guangdong province, the change of the whole manufacturing gravity depends on the transfer and upgrading of manufacturing industry. The longest moving distance is labor-intensive manufacturing, the shortest is capital-intensive manufacturing. The center of gravity of labor-intensive manufacturing industry is in the southwest and northeast direction of manufacturing overall center of gravity; the moving trajectory presents an eastward ray, moving 
distance of 26.5588 kilometers, of which the maximum moving distance is $10.13162 \mathrm{~km}$ in 2009. The main reason is the double transfer policy, which brought about the decrease of the proportion of the labor-intensive manufacturing industry in Dongguan, Shenzhen and Zhanjiang, and the proportion of Shantou, Shanwei, Jieyang and Chaozhou increased. This led to the 2009 manufacturing center of gravity relative to 2008, the northeast direction of movement, and the larger distance. For labor-intensive manufacturing industry, the main cost is labor. The east, west and north of Guangdong have relatively lower labor cost than that in the Pearl River Delta area. With the improvement of traffic conditions, labor-intensive industry transfer has obvious advantages from the traditional location advantage theory. Accordingly, the change of its center of gravity is also more obvious. Capital-intensive manufacturing mainly distributes in Guangzhou and Foshan, because Guangzhou and Foshan are in the northwest direction of the manufacturing overall center, the corresponding capital-intensive manufacturing centre of gravity is in the northwest direction of the overall manufacturing industry, the movement is $1.228 \mathrm{~km}$. For the capital-intensive manufacturing industry, the spatial distribution is more balanced, due to the restriction of resource endowments and natural resources. The technology-intensive manufacturing gravity in the southeast direction of the overall manufacturing gravity, its moving distance is $2.6072 \mathrm{~km}$. For technology-intensive manufacturing industry, it is influenced by such factors as specialization level, labor pool sharing and knowledge spillover. Based on Marshall's externality, when the enterprise chooses the location, the cities of high modernized level and the concentration of the university and scientific research are to form the aggregation effect. Shenzhen as the main agglomeration of technology-intensive manufacturing industry, its position as a growth pole is very difficult to change, so its spatial distribution is small. Technology-intensive manufacturing industry is the largest deviation from the geographical center, which shows that its spatial diversity is the greatest.

Thirdly, the grey relational analysis shows that: the strongest correlation with the overall manufacturing gravity is technology-intensive manufacturing industry; the second is capital-intensive manufacturing; labor-intensive manufacturing is the weakest link. The growth of technology-intensive manufacturing industry has the most obvious effect on the change of the overall center of gravity of manufacturing industry, which means that the difference of the overall growth of manufacturing industry in Guangdong province is more reflected in the technology-intensive change.

Finally, from the moving distance and trajectory of the manufacturing gravity, it can be seen that the manufacturing transfer policy has little influence on the overall manufacturing gravity, that is, the effect of manufacturing transfer on the balance development of manufacturing industry in Guangdong province is not obvious. As the technology-intensive manufacturing gravity is the most relevant to the whole manufacturing gravity, the moving path of technology-intensive 
manufacturing industry is closest to that of the whole manufacturing, so we should further strengthen the manufacturing upgrading of underdeveloped areas and improve the technical development level of undeveloped areas, so as to promote the balanced development of manufacturing space distribution in Guangdong province. Therefore, the government should carry out effective guidance and intervention, give technical and organizational guidance and help, promote the technological level of transfer industry, strengthen the construction of scientific research level, and introduce relevant professionals and technology to further promote the coordinated development of Guangdong province.

On the one hand, this study is based on 21 cities in Guangdong province, the county level data will be more accurate description of Guangdong province; on the other hand, this study is based on the gravity analysis, probes into the change of the spatial pattern of manufacturing industry in Guangdong province, and quantitatively describes the influencing factors, it is essentially descriptive analysis. On the basis of this research, it will be the main direction of the next research to quantitatively analyze the factors that cause the change of the manufacturing space pattern.

\section{References}

[1] Krugman, P. (1991) History and Industry Location: The Case of the Manufacturing Belt. AEA Papers and Proceedings, 81, 80-83.

[2] Brulhart, M. (2001) Evolving Geographic Concentration of European Manufacturing Industries. Weltwirtschaftliches Archiv, 137, 215-243. https://doi.org/10.1007/BF02707264

[3] Sohn, J. (2004) Do Birds of a Feather Flock Together: Economic Linkage and Geographic Proximity. The Annals of Regional Science, 38, 47-73. https://doi.org/10.1007/s00168-003-0145-x

[4] Sjöberg, Ö. and Sjöholm, F. (2004) Trade Liberalization and the Geography of Production: Agglomeration, Concentration, and Dispersal in Indonesia's Manufacturing Industry. Economic Geography, 80, 287-310. https://doi.org/10.1111/j.1944-8287.2004.tb00236.x

[5] Fan, J.Y. (2004) Market Integration, Regional Specialization and Tendency of Industrial Agglomeration: An Implication for Regional Disparity. Social Sciences in China, 6, 39-51.

[6] Wei, B.T. and Zhou, J.W. (2008) Economic Integration, Regional Specialization and Spatial Distribution of Manufacturing in China. Economic Management, 30, 120-125.

[7] Ke, R. and Qin, L. (2013) Study on Spatial Difference of Labor Productivity of Manufacturing Industry in Yangtze River Delta. Regional Economic Review, 2, 56-61.

[8] Amos Jr, O.M. (1988) Unbalanced Regional Growth and Regional Inequality in the Later Stage of Development. Regional Science and Urban Economics, 549-566. https://doi.org/10.1016/0166-0462(88)90026-9

[9] Williamson, J.G. (1965) Regional Inequality and the Process of National Development: A Description of the Patterns. Economic Development and Cultural Change, 13, 3-45.

[10] Grether, J.-M. and Mathys, N.A. (2010) Is the Word's Economic Center of Gravity 
Already in Asia. General \& Introductory Geography, 42, 47-50.

[11] Xu, J.H. and Yue, W.Z. (2001) Evolvement and Comparative Analysis of the Population Center Gravity and the Economy Gravity Center in Recent Twenty Years in China. Scientia Geographica Sinica, 5, 385-389.

[12] Fan, J. (1996) The Economic Analysis of Rural Industrialization of China and the Difference of Provincial Development Level. Geographica Sinica, 5, 398-407.

[13] Zhou, M.L. (2000) The Economic Center, Regional Disparities and Coordinated Development. Social Sciences in China, 2, 42-53 + 206.

[14] Sun, X.H. (2001) The Study of Movement of Industrial Weight Center Basing on GIS and Its Sustainable Development Measurement in Shandong Province. GeoInformation Science, 1, 27-31.

[15] Qiao, J.J. and Li, X.J. (2005) The Shift Route of Chinese Economic Gravity Center in Recent 50 Years. Areal Research and Development, 1, 12-16.

[16] Feng, Z.X. and Huang, J.S. (2005) Dynamic Variation Track and Contrastive Research of Economic Gravity Centre and Industrial Gravity. Economic Geography, 2, $249-254+269$.

[17] Yang, L., Du, P. and Xia, B. (2009) Contrastive Research of Economic Gravity Centre and Industrial Gravity in Guangdong Province. Science and Technology Management Research, 7, 70-72.

[18] Yan, J. and Wang, Z.H. (2010) Variation Track and Contrastive of Economic Population Gravity and Industrial Gravity for 30 Years. Journal of Nanjing Population Management Cadre Institute, 26, 34-38.

[19] Cao, Z.L. and Chen, S.L. (2011) Spatial Evolution and Dynamic Analysis on Economic Barycenter and Industrial Centre of Gravity in Fuzhou Municipality Based on the GIS. Subtropical Soil and Water Conservation, 2, 22-27 + 32 .

[20] Wu, S.M. and Li, S.T. (2010) Space Distributing and Dynamic Variation Track of Manufacturing Industrial Gravity Centre of China from 1980 to 2007. Economic Management, 4, 27-35.

[21] Su, L. and Zhang, X.P. (2012) Research on Spatial Distribution of the Manufacturing in Beijing and Its Decomposition of Center of Gravity. Progress in Geography, 4, 491-497.

[22] Yang, L.G. and Xie, R. (2014) Research on the Impact of Rising Labor Cost on Manufacturing Structure Upgrading-An Empirical Analysis Based on the Data of Sub-Sectors of Chinese Manufacturing. China Soft Science, 12, 136-147.

[23] Bai, X. (2015) The Spatial Evolution of China's Economic Center of Gravity and the Decomposition of the Industrial Center of Gravity. Inquiry into Economic Issues, 6 , $18-24$. 